\title{
Netcare - KPMG breached client privilege to boost Competitions Commissions probe
}

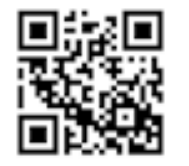

Private hospital giant Netcare claims that its former auditors, KPMG, cynically breached client privilege by sharing detailed information they had obtained from Netcare with the Competitions Commission - after silently agreeing to help the Commission with its probe.

Melanie da Costa, Director of Strategy and Policy at Netcare (and chairperson of the Hospital Association of South Africa), said that a KPMG team had spent three years helping Netcare prepare itself for the healthcare market inquiry. It had unfettered access to Netcare's strategy, planning, competitive positioning and other business data. This auditing team then allegedly shared this data with another KPMG team, which had, unknown to Netcare, taken on the Competitions Commission advisory and data-gathering brief - raising serious conflict-of-interest issues. She said that the wrangle was between Netcare and KPMG, not the Competitions Commission, and that it was not a delaying tactic, as a KPMG executive claimed, adding: 'We have nothing to hide - I can tell you that, hand on heart - KPMG are disingenuously trying to portray that, but it's most definitely not the issue.'

$\mathrm{Da}$ Costa was referring to the 'totally irresponsible' accusation by KPMG's head of legal services, Olaff Abraham van Niekerk, that Netcare's court action was part of an 'Operation Kotov' (a chess move allegedly designed to delay the opponent, in this case ostensibly the Commission, thus hurrying them into a blunder). She said that when KPMG refused to provide Netcare with assurances that it would abide by accepted confidentiality rules, Netcare took them to court. On 29 October last year, the High Court in Gauteng ordered all KPMG staff assisting the Competitions Commission to provide 'affidavits of assurance' that KPMG's internal 'Chinese walls' had not been breached - in other words, to swear under oath that they had not breached confidence by obtaining privileged information from their colleagues who worked for Netcare. Da Costa said that KPMG belatedly provided Netcare with these affidavits in December last year - revealing that its staff had in fact breached the court order. She claims that KPMG had up to 50000 documents referencing Netcare (which KPMG refused to hand over). Far from Netcare stalling any Competitions Commission probe, it was KPMG who on 6 January this year requested a court postponement to 20 May.

\section{Simple solution - hand over info to independent attorneys, says Netcare}

'They could have, and still can at any stage, give independent attorneys access to the information they have on Netcare to ensure this matter is speedily resolved, but have chosen not to', Da Costa emphasised. Netcare is asking the High Court to rule that: (i) KPMG breached its earlier ruling; (ii) KPMG hand over all relevant documents to independent attorneys to assess their content; and (iii) KPMG cease all work 
for the Competitions Commission until the issue is resolved.

KPMG's Van Niekerk claimed in court papers that Netcare went to court 'as part of Operation Kotov', adding: 'Project Kotov seems a very apt name ... Kotov is a Russian surname, the most famous bearer of which was one Alexander Kotov. He was a famous chess grandmaster ... He describes a situation when a player thinks very hard for a long time [about] a complicated position but does not find a clear path, then, running low on time, quickly makes a poor move, often a blunder.' Van Niekerk maintains that Netcare's broad strategy is to force the Commission to delay the inquiry for as long as possible and, because of the long delay, cause the Commission to move quickly. He says KPMG's work for Netcare was 'technical' in nature.

\section{KPMG: Netcare 'hiding something'}

Court papers reveal that the Commission suspects that Netcare wants to hide something. The Commission says: 'Netcare also fears that information provided to the inquiry may lead the commission to initiate a complaint against it or refer it to the tribunal.' The tribunal has the power to both subpoena evidence and fine companies $10 \%$ of their annual turnover for pricefixing or illegal anti-competitive behaviour. Commission spokesperson Trudie Makhaya told Izindaba that any fines would be a byproduct of the wider investigation, which was aimed at 'bigger competition policy problems'. 'If we suspect price fixing we can open a new probe and run with it (via the Competition Tribunal), imposing penalties, but that's not our primary purpose.'

Explaining the Kotov reference, Da Costa told Izindaba that in 2011 Netcare engaged a professional external company to work with its management to assess strategy in the context of various possible future South African healthcare scenarios. They had used chessboard analogies to depict these scenarios, named Kotov, Stalemate, Gambit and Grandmaster. In the UK, where Netcare provides substantial services to the National Health Service set-up, this scenario planning was analysed in the context of the Olympics soon to be hosted in London (scenario analogies being Gold, Silver, Bronze and Off the Podium).

'The local Kotov scenario was not a response to the more recently announced market inquiry here. KPMG are simply seeking to deflect attention away from their own inappropriate behaviour by making unfounded allegations', she said. The

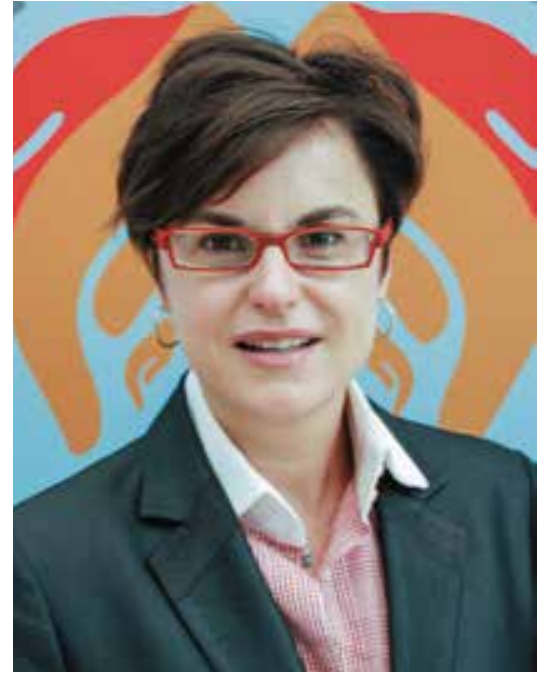

Melanie da Costa, Director of Strategy and Policy at Netcare. Picture: Chris Bateman.

name 'Project Kotov' arose from Netcare's constructive engagement with various external stakeholders, including senior government officials, politicians, academics, opinion formers and business executives, with the aim of stimulating ideas on how to increase access to quality healthcare in South Africa. The 'Kotov scenario' was intended to reflect a potential narrative of economic growth, but low social cohesion - with the likelihood of additional regulation perceived to be relatively high.

'The issue has nothing to do with the Competitions Commission. It's actually about a professional services firm (KPMG) and its client. It's about the breach of good faith and the duty of care a professional services firm has to its client. It's unacceptable behaviour and we'll protect our proprietary information and intellectual capital in the interests of Netcare and its shareholders', she added.

\section{Commission aims to restore order to 'law of the jungle' market}

Amended legislation for the first time gives the Commission powers of subpoena with attendant fines for non-co-operation unlike the probe into the banking sector in 2008, which depended entirely on companies' voluntary participation and resulted in some impact on bank charges but little change to the way banks do business The health sector probe is a long-awaited response to a 'law of the jungle' situation that has evolved in the unevenly regulated private sector where, among other things, specialists can charge up to $500 \%$ of medical aid prices and patients must cough up the payment shortfall, in addition to their everrising medical aid subscriptions. Medical schemes argue that they are unable to act in the best interests of their members because of their lack of bargaining power relative to the powerful hospital groups (a controversial Competitions Commission ruling in 2005, aimed at preventing collective price setting without any regulatory oversight, halted price negotiations between the Board of Healthcare Funders, the Hospitals Association of South Africa and the South African Medical Association). New research by economics consultancy Econex on the market concentration of private hospitals, medical schemes and administrators purports to show that, contrary to concerns over growing concentration, the private hospitals market has in fact remained flat since price negotiations were banned. Econex said it had constructed a bed database that allowed it to calculate market share accurately, and found that most consolidation in the hospital market took place before the ban.

\section{Setting tariff guidelines \\ - no consensus}

With the Health Professions Council of South Africa and the national health department reluctant to grasp the volatile issue of setting patient tariff guidelines, stakeholders have been operating in a void with, among other legal battles, court applications seeking the 'proper' legal interpretation of 'pay in full' for Prescribed Minimum Benefits bogging down in technicalities. It's become a 'zerosum game', with each stakeholder operating at the expense of the other and the patient all but forgotten in the mix. As medical inflation soars, medical aids blame collusion between specialists and private hospitals, plus complicity between patients and doctors in abusing hospital plans. They cite the explosion of powerful but expensive new medicines and technologies and the fee-forservice payment system, plus the fragmented structure in which doctors, hospitals and all other providers work in silos, with almost no co-ordination between them. Specialists, on their side, point to almost intolerable workloads resulting from serious shortages in their numbers, rampant brokerage and administration and managed-care costs in medical aids, plus soaring litigation insurance costs. It's a toxic, society-unfriendly mix that has placed huge pressure on the Competitions Commission to come up with provisional findings and recommendations by its target date of October 2015.

Briefing stakeholders in mid-May, the Chairman of the Health Inquiry, former Chief Justice Sandile Ngcobo, said that its success was inextricably linked to the 
open and transparent airing of views and information. He said his hand-picked team of experts was developing a set of ideas about how harmful effects of competition might arise in the relevant markets. Dubbed 'theories of harm', these were hypotheses or tools enabling them to identify whether there were features that might prevent, distort or restrict competition in the private healthcare markets. He emphasised that theories of harm were not findings of harm, but simply analytical tools to guide analysis. 'They will be deepened and revised as the inquiry's thinking develops', he added. Harm to competition could come from market power, including market concentration, barriers to entry and expansion, imperfect information, regulatory framework and vertical relationships. Judge Ngcobo said the issuing of 'information requests' would be done by August this year. The first round of public hearings would be held between 1 March and 30 April next year. Beginning in May next year, the inquiry would analyse and review all information gathered, putting provisional findings and recommendations out for public comment by October 2015 . Quizzed on how the Netcare court challenge to its auditors might affect these timelines, Competitions Commissioner Tembinkosi Bonakele would only say that the probe is live and happening, just slower than anticipated'.

\section{Chris Bateman}

chrisb@hmpg.co.za

S Afr Med J 2014;104(6):395-397.

DOI:10.7196/SAMJ.8438 